\section{Esferas públicas, crisis política e internet: el surgimiento electoral de Podemos}

\section{Public spheres, political crisis and the Internet: the rise of the Podemos party}

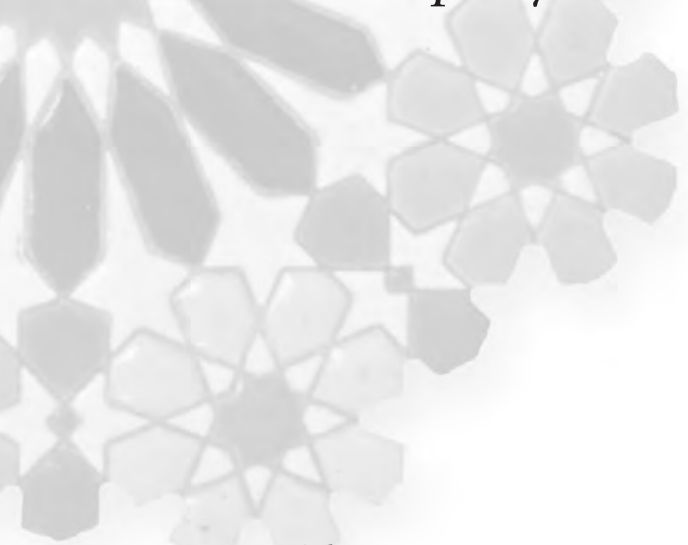

Ariel Jerez

Profesor, Facultad de Ciencias Políticas y Sociología/ Universidad Complutense de Madrid (UCM). Campus de Somosaguas 28223 - Pozuelo de Alarcón - Madrid - España arieljerez@cps.ucm.es

Sergio D'Antonio Maceiras

Profesor, Facultad de Trabajo Social/UCM. Campus de Somosaguas

28223 - Pozuelo de Alarcón - Madrid - España sergiodantonio@ucm.es

Enrique Maestu

Investigador, Facultad de Ciencias Políticas y Sociología/UCM. Campus de Somosaguas 28223 - Pozuelo de Alarcón - Madrid - España emaestu@ucm.es

Recebido para publicação em setembro de 2014. Aprovado para publicação em outubro de 2015.

http://dx.doi.org/10.1590/\$0104-59702015000500003
JEREZ, Ariel; MACEIRAS, Sergio D'Antonio; MAESTU, Enrique. Esferas públicas, crisis política e internet: el surgimiento electoral de Podemos. História, Ciências, Saúde - Manguinhos, Rio de Janeiro, v.22, supl., dez. 2015, p.15731596.

\section{Resumen}

El surgimiento del partido político Podemos en España, en el contexto de crisis de representación política, se explica en una perspectiva de interacciones transformadoras entre esferas públicas, movimientos sociales y nuevas tecnologías. La coyuntura abierta tras el ciclo $15 \mathrm{M}$ ha propiciado un nuevo diagnóstico político recogido por Podemos, activamente puesto en circulación en las redes sociales, verdadera plataformas de difusión electoral y organizativa para partidos de bajos presupuestos. Analizando Twitter y Facebook se confirma su veloz proceso de crecimiento y liderazgo en redes, el perfil de sus seguidores y publicaciones con mayor impacto y difusión de estos nuevos discursos. Se concluye analizando los retos de este tipo de partidos para incorporarse al panorama político español y europeo.

Palabras clave: esferas públicas; crisis; internet; Podemos; España.

\section{Abstract}

The rise of the political party Podemos, within the context of a crisis in political representation, can be explained from a perspective of transformative interactions between public spheres, social movements and new technologies. The emergence of the $15 \mathrm{M}$ movement allowed Podemos to offer a new diagnosis of politics that has been actively promoted on social media, which represent a true campaign platform for low-budget parties. An analysis of Twitter and Facebook reveals the rapid growth of Podemos, its prominence on social networks, the profile of its followers and its most influential publications in these new discourses. Lastly, we analyze the challenges for this type of party in terms of incorporating into the political panorama in Spain and in Europe.

Keywords: public spheres; crisis; Internet; Podemos; España. 
Liseng a escena política española ha vivido importantes transformaciones desde el surgimiento de Podemos, en enero de 2014. El impacto de un discurso crítico innovador con un liderazgo joven se ha dejado sentir en un deteriorado sistema político-mediático ya cuestionado con "movilizaciones indignadas" surgidas del 15M de 2011. ${ }^{1}$ Sus pesadas barreras institucionales y culturales se han empezado a mover con la estrategia relámpago con la que el nuevo partido ha encarado una coyuntura electoral vertiginosa, enfrentando cinco citas electorales en 18 meses.

La presencia televisiva del joven profesor de ciencia política Pablo Iglesias Turrión ha estimulado que, en el contexto de crisis, haya aumentado la atención pública a los programas de debate político. La competitividad entre cadenas ha aumentado su número en las cadenas generalistas y ampliado la ampliación del espectro ideológico de los invitados en los nuevos programas, donde los portavoces de Podemos han pasado a tener representación televisiva cuasi permanente, antes reducida al bipartidismo en este tipo de programas.

La juventud de los principales portavoces de Podemos ha obligado al resto de formaciones a renovar sus principales cuadros que han llegado a rebajar la edad de sus liderazgos entre dos y tres décadas, como en los casos Pedro Sánchez en el Partido Socialista y Alberto Garzón en Izquierda Unida. El Partido Popular en el gobierno también ha cambiado sus principales portavoces institucionales y ha comenzado una veloz operación de sustitución de los rostros más reconocibles de lo que hoy, más que nunca, es percibida como "la vieja guardia" de partido.

Los cinco escaños alcanzados en el Parlamento Europeo, en su primera cita electoral del 25 de mayo (7,98\% de los votos), alarmaron a las élites políticas y económicas. En junio, un representante de la banca declaraba públicamente la necesidad de contar con "una especie de Podemos de derechas" que se logró construir a gran velocidad con un sólido apoyo mediático en torno al partido Ciudadanos en el primer trimestre de 2015. A pesar de ser objeto de una constante estrategia mediático-demoscópica de escándalos con el objetivo de desgastar su "novedad", Podemos logró ampliar sus resultados electorales en las siguientes citas regionales y municipales, y sigue disputando las primeras posiciones en los sondeos.

En este artículo se analizan los primeros meses de crecimiento en las redes sociales como elemento central de su innovadora estrategia tecno-política, sin duda un momento fundamental para observar algunas singularidades de su capacidad discursiva y su impacto en las redes sociales para generar atención pública en un contexto político como el español. En un primer apartado se exploran las esferas públicas como marco analítico necesario para dar cuenta de cómo las dinámicas de disenso promovidos por la sociedad civil crítica empiezan a participar de los procesos mediáticos que orientan los sistemas político-culturales. En un segundo momento se abordan algunas características del proceso de democratización política como variable de contextualización necesaria para entender la estrategia de este joven partido donde la innovación discursiva y comunicacional han sido sus principales palancas para producir una fuerte demanda de cambio político en España. El análisis de los datos de sus seguidores en redes y de los mensajes de mayor viralidad en este periodo, desarrollados en los siguientes apartados, muestran tanto el componente de renovación generacional abierto por este proyecto político como su cuestionamiento reconstituyente de las bases discursivas consensuadas en el relato político de la llamada transición modélica a la democracia (Navarro, 2002, 2006). 


\section{Esferas públicas, movimientos sociales y crisis política}

La discusión contemporánea sobre esferas públicas ha venido ampliando el foco de análisis centrado en los actores sociales y políticos hacia el de las regulaciones institucionales y culturales de los espacios públicos y mediáticos como espacios clave de producción de ideologías, identidades y agendas. En buena medida sobre estas tramas discursivas se despliega el conflicto social y el diálogo institucional que procesa los problemas colectivos, decantando cuáles serán definidos como intereses públicos y privados para ser atendidos (o no) por cada Estado en un contexto histórico nacional dado.

Las esferas públicas se presentan como un esquema de análisis cada vez más lejos de los postulados liberales de su primigenia formulación habermasiana, que la consideraba como un espacio unificado e igualitario en el que se desarrollan deliberaciones racionales orientadas para el entendimiento mutuo y el reconocimiento público (Habermas, 1981). Son abordadas como complejos campos de disputa por la hegemonía política e ideológica, donde la protesta y la propuesta de "públicos fuertes y públicos opositores" no solo dialogan para incidir racionalmente en los procesos de toma de decisiones, sino que también persiguen la autonomía sociopolítica constituyendo subjetividades críticas y confrontativas, portadoras de nuevas demandas de reconocimiento material y simbólico. A medida que avanza la crisis de la globalización neoliberal, en las calles, plazas, parlamentos y al interior de los medios de comunicación, se observan dinámicas discursivas cargadas de emocionalidad y humores que buscan realinear los públicos en lógicas de consentimiento y disentimiento (Landi, oct. 2013; Kluge, Negt, 2001; Fraser, 1997).

Frente a la "esfera pública central" donde se expresa la hegemonía ideológica de las élites con capacidad de proyectar sus demandas como "opiniones agregadas" (audiencias, sondeos y urnas), las "esferas públicas periféricas" son dinamizadas por diferentes públicos que crean "opiniones discursivas" movilizadas tanto en relaciones cara a cara como por medios alternativos que operan como contrapoderes socio-comunicacionales (Castells, 2009; Jerez, Sampedro Blanco, López Rey, 2008; Sampedro Blanco, 2000). El control sobre el acceso y gestión de la visibilidad pública de los actores y movimientos de la sociedad civil en los medios radiotelevisivos convencionales, todavía la principal baza hegemónica de la política mediática, es por momentos rebasado por redes de comunicación alternativa y contra información que buscan hackear el periodismo e identidades ciudadanas en movimiento que se reconstruyen en un nuevo ecosistema cultural mediático, que pugna también por su regulación, con una filosofía colaborativa y de código abierto que contempla la tecnología como un factor político (Castells, 2012; Sadaba, 2012; Della Porta, Diani, 2011; Subirats, 2011; Mancini, 2011; Curran, 2005; Mattelart, 2002).

Si bien los partidos políticos tradicionales han ido haciendo un uso progresivo de la Web 2.0, sigue siendo para la mayoría una estrategia auxiliar y subalterna a la campaña de comunicación offline. No obstante, como apuntan diversos estudios, las pautas de consumo informativo y participación política van cambiando tanto en los activistas en particular como en la ciudadanía en general. Progresivamente, se han visto cómo, en distintos países, en las elecciones se empieza a constatar la presencia de cibervoluntarios que se implican de forma creciente en la trasmisión de mensajes con estrategias cada vez más programadas y 
protocolizadas por los equipos de campaña (Sampedro Blanco, 2011, 2014; Anduiza et al., 2010; Anduiza, 2009).

No obstante, la coyuntura de crisis y los procesos de movilización abiertos implican, de manera creciente, las redes de los movimientos sociales en los procesos políticos. En el caso de Podemos, se constata cómo el tránsito de la lógica de movimiento al partido ha sido facilitada por una mediación tecnológica que posibilita un entorno de deliberación horizontal, de participación distribuida y estructura descentralizada ya experimentada por las "movilizaciones indignadas" (Romanos, Sadaba, 2015). Una nueva lógica de acción colectiva, apoyada en los recursos de la red, hace confluir culturas activistas de movimientos, partidos y de otras organizaciones y colectivos de la sociedad civil en nuevos formatos partidarios que aprovechan la sinergia de una "comunicación multicapa" (Toret, 2015, p.131). Las dinámicas territoriales de movilización offline, que se han ido articulando con audiencias televisivas masivas, le han permitido la creación de perfiles en las redes sociales con gran número de seguidores. La combinación de elementos de movimiento en red con la forma de liderazgo de corte populista logra optimizar un circuito que, como se refleja en el análisis empírico, consigue un crecimiento exponencial en las redes sociales - que si bien exige un reconocimiento del sistema mediático que no necesariamente beneficia la visibilidad de su imagen pública con su tratamiento recibido en las parrillas de programación (Toret, 2015; Sampedro Blanco, 25 mar. 2015).

\section{El contexto de crisis en España}

La crisis financiera mundial abierta a final de 2007 ha sumergido a España en la crisis social y política más grave desde la salida del franquismo. El modelo productivo e institucional pactado por las fuerzas parlamentarias en aquel momento empieza a mostrar sus limitaciones históricas.

El débil "sistema de justicia" muestra dificultades para contener una corrupción cada vez más visible que afecta a las máximas autoridades políticas y económicas (miembros de la Casa Real, ministros y presidentes regionales y estatales; altos representantes empresariales). Al tiempo, fuertes tensiones identitarias atraviesan el Estado de las Autonomías, reforzándose los polos independentistas de orientación secesionista. Los olvidados crímenes de lesa humanidad, cometidos durante la dictadura franquista, buscan en el extranjero amparo en la justicia universal, afectando a la imagen internacional de España. La escandalosa política de salvataje bancario en un contexto de recortes de gasto público y en políticas sociales (el llamado críticamente "austericidio") ha ahondado la brecha social. Los continuos recortes en prestaciones afecta la calidad de los servicios en sanidad y educación, apareciendo cifras de desigualdad y pobreza (infantil y energética), inimaginables hasta hace algunos años (Cáritas, 2013). En el caso de la vivienda, la leonina política hipotecaria está provocando centenas de miles de desahucios, donde los hipotecados tienen que entregar la vivienda y seguir pagando los préstamos (no existe la llamada "dación en pago", existente en la mayoría de los países europeos y en EEUU). La crisis de representación comienza a reflejarse demoscópicamente. El voto bipartidista, que recogía más del $80 \%$ de los sufragios, se encuentra por debajo de la barrera psicológica del $50 \% .^{2} \mathrm{Al}$ mismo tiempo, los políticos son considerados el segundo 
problema de los españoles tras el desempleo, y su confianza ha caído del 43\% al 5\% en los últimos cinco años.

Es pertinente subrayar el importante componente generacional de esta crisis. En relación al desempleo, las tasas entre los menores de 35 duplican la de los adultos, superando en algunas regiones el 60\%. También se constatan importantes diferencias salariales y contractuales en el mercado de trabajo, así como el progresivo aumento de la edad de jubilación que afecta a los más jóvenes. Son el colectivo más afectado por la emigración: en 2012, son 302.623 los jóvenes (entre 15 y 29 años) con nacionalidad española que residen en otros países según el Padrón de Españoles Residentes en el Extranjero, perteneciente al Instituto Nacional de Estadística.

Hasta hace pocos años, los posicionamientos críticos de la sociedad civil han tenido una presencia débil y marginal en una esfera pública marcada por un sistema mediático y una dinámica cultural altamente mercantilizada y espectacularizada. Enraizada en los grandes consensos de la transición, aquel diseño mediático-cultural tenía por principal objetivo la desmovilización sociopolítica e ideológica de la oposición antifranquista para consolidar los pactos entre élites del viejo y el nuevo orden. La llamada hoy críticamente "cultura de la transición", caracterizada por su gubernamentalismo y propagandismo a favor de los consensos elitistas forjados en la salida de la dictadura, ha sido garante del relato político ejemplar. Celebrando sus acuerdos en todo momento presentados pacíficos y pragmáticos, gracias a unas elites virtuosas responsables que supieron pactar y olvidar, se oculta durante las décadas democráticas el papel de la movilización social en la transición al tiempo que se sigue estigmatizando, como peligroso, cualquier expresión de conflicto y desorden bajo el peligro de volver a sumir el país en el caos. El bipartidismo beneficiario de los dispositivos institucionales de producción, de mayorías parlamentarias, no realizó ninguna pedagogía crítica de estos marcos ideológicos narrativos que perduran hasta hoy con la marginación del pensamiento crítico en torno a la realidad social (VVAA, 2012; Fernández-Savater, 2012). Sin embargo, al calor de la crisis, han aumentado las estructuras de oportunidad mediáticas para las redes críticas, derivadas tanto de internet como de reajustes en el sistema mediático. ${ }^{3}$ El trabajo y el capital social y comunicacional, acumulado a lo largo de la última década y media (contracumbres del movimiento altermundista, movimiento de memoria histórica etc.), han hecho florecer una gran cantidad de iniciativas comunicacionales y culturales que abordan temas antes considerados tabú (como por ejemplo la impunidad del franquismo, la crítica a la monarquía, al modelo económico empresarial que subyace en la llamada "burbuja inmobiliaria").

En este contexto entra en declive el relato hegemónico de una transición a la democracia "modélica". Se abre una estructura de oportunidad favorable a un marco interpretativo de una voluntad política "destituyente-constituyente", que asomó ya al principio de la inesperada movilización de 1@s indignad@s del 15M (Los partidos..., 29 oct. 2013; Monedero, 2011). Desde estas esferas periféricas se empieza a desarrollar una perspectiva crítica también sobre el desarrollo de las instituciones participativas, puestas en marcha en las últimas décadas en Europa (Jerez, Ramos, Allegretti, 2011, 2012). Son ejemplos de ello la Plataforma de Afectados por las Hipotecas y su resistencia activa en los desahucios (Inurrieta et al., 2014; Romanos, 2011); la movilización desobediente de presión contra instituciones (Rodea el Congreso, Rodea la Bolsa) o los "escraches" a cargos públicos y representantes empresariales. Públicos 
fuertes y opositores se activan desde nuevos y viejos espacios de organización social, como los ya tradicionales centros sociales autogestionados o las asociaciones vecinales, pero también desde las redes sociales y el ciberespacio.

Las interacciones entre las distintas redes movilizadas con los partidos políticos no han sido fáciles y han estado históricamente marcadas por las tensiones. No obstante, a pesar de su perfil asambleario y horizontal refractario de las dinámicas representativas, algunos partidos de izquierda llegan a debatir la necesidad de contar con un referente electoral propio para enfrentar la crisis. Iniciativas bienintencionadas pero que no lograron generar ningún acuerdo como para representar electoralmente estos movimientos poliédricos.

Los nuevos partidos que se presentan a las elecciones europeas y cuentan entre sus promotores con activistas con trayectoria en los movimientos sociales, no se han librado de las reticencias y reservas de espacios basistas-asamblearistas del movimiento. La Red Ciudadana-Partido X, promovido por ciberactivistas, pretende activar dinámicas participativas y de fiscalización que limiten las tendencias oligárquicas de la vida partidaria (Alcazan, 2012; Subirats, 2011) a través del uso masivo del potencial tecnopolítico de la red. Por otra parte, Podemos es el que está logrando captar la atención más masiva entre las redes de activistas y públicos movilizados en el ciclo post-15M. Con su manifiesto de lanzamiento, abría la polémica con la izquierda parlamentaria al reclamar: "Una candidatura que avance desde los espacios ya logrados y que logre avanzar más allá de la parálisis actual. Una candidatura que 'mueva ficha' para convertir el pesimismo en optimismo y el descontento en voluntad popular de cambio y apertura democrática". ${ }^{4}$

Sin duda las elecciones europeas abrieron una ventana de oportunidad favorable para los nuevos partidos en un contexto políticamente fluido. Al realizarse sobre una circunscripción nacional única permiten la concentración del voto, al contrario que el sistema electoral español, uno de los dispositivos normativo-institucionales más denunciados por las protestas del $15 \mathrm{M} .^{5}$

\section{Podemos: nuevo protagonismo popular y ciudadano}

El 14 de enero de 2014 se lanzaba el manifiesto "Mover ficha: convertir la indignación en cambio político" en internet, y el día 17 se presentaba en público el desafío de conseguir cincuenta mil firmas de apoyo en 15 días para lanzar una candidatura ciudadana, encabezada de Pablo Iglesias, a las elecciones europeas. Este apoyo masivo fue conseguido en las primeras 36 horas, lo que entusiasmó no sólo al grupo promotor sino a muchos activistas que decidieron participar en la iniciativa, que se articula sobre dos espacios organizativos diferenciados. Por un lado, el núcleo intelectual que desarrolla la estrategia de la campaña, conformado principalmente por profesores, estudiantes y egresados de las Facultades de Ciencias Políticas y Sociología y de Filosofía de la Universidad Complutense, agrupado en la productora televisiva La Tuerka/Producciones Con Mano Izquierda. Por otro, Izquierda Anticapitalista, un partido hasta el momento extraparlamentario, con una reconocida trayectoria de trabajo junto a diversos movimientos sociales que constituye el músculo organizativo inicial.

Señalamos algunos aspectos de la trayectoria del grupo promotor y de su portavoz, Pablo Iglesias, relevantes para comprender el innovador proceso de reelaboración ideológica y 
discursiva emprendido en este nuevo espacio político. Desde el punto de vista del liderazgo colectivo conviene destacar la trayectoria compartida de varios miembros del equipo en el espacio universitario, donde la facultad mencionada es una referencia para los movimientos sociales madrileños. En distintas redes y momentos, este grupo de profesores e investigadores (antiguos estudiantes) comparten el ciclo político altermundista, impulsando distintas líneas de reflexión y experimentación intelectual y mediática, que servirán de base para participar profesionalmente en actividades de asesoría política y electoral en el nuevo ciclo de gobiernos progresistas latinoamericano como para promover su propio espacio comunicacional, aliándose a un periódico comercial público y a una televisión comunitaria con la conducción del programa La Tuerka, que desde finales de 2013 pasa a realizarse en el plató televisivo de este diario con cuatro ediciones semanales de noventa minutos. ${ }^{6}$

De la trayectoria política y profesional de Pablo Iglesias cabe reseñar además de su juventud y su especialización "mediactivista", su marcado carácter militante (primero en las juventudes comunistas y después en el sector "desobediente" del movimiento antiglobalización). En este sentido, sus trabajos en el campo televisivo han servido para que los públicos progresistas hayan empezado a superar la orfandad ideológica impuesta por los medios que sostienen la "cultura de la transición". Los programas en medios alternativos, La Tuerka y Fort Apache (HispanTV), con una horquilla de entre 15.000-70.000 espectadores en streaming y amplios visionados en diferido, han conformado una masa crítica de consumidores de información crítica y discursos radicales, fundamental para dinamizar las redes sociales. Su participación en programas de debate en las televisiones comerciales le ha abierto simpatías en amplios públicos, a pesar de haber incomodado al establishment periodístico. " "Con esa pinta de nazareno estás hecho un Barrabás" es un comentario de un referente periodístico neoconservador, ilustrativo tanto de esa disrupción en el mainstream informativo como del imaginario ideológico normalizado por los medios españoles. Estos tres años de programación propia y ajena de Iglesias han constituido, posiblemente, el mayor espacio de una experimentación política mediática subalterna de la reciente democracia española fundamental, el espacio desde donde se empezó a articular la sinergia de la mencionada comunicación multicapa. ${ }^{8}$

La dimensión generacional de la crisis forma parte del propio relato que acompaña la emergencia de Podemos. Cuando en su presentación Iglesias señaló la necesidad de "mover ficha" para sacar a la izquierda de su parálisis, puntualizó que "solo tres personas podíamos dar este paso" (todas ellas menores de 40 años): además de él, Ada Colau, la reconocida militante social del post-15M (hoy ya alcaldesa de Barcelona) y Alberto Garzón (que acaba de conseguir el relevo generacional en su partido como nuevo secretario general en Izquierda Unida). Una dimensión generacional sobre la que pivota una lectura crítica del relato político reciente e impulsa un nuevo enmarcamiento político que subraya la confrontación ideológico de un nuevo espacio que se presenta como movimiento ciudadano con voluntad ganadora y constructor de mayorías sociales y electorales que apuesta por ir más allá del eje izquierda y derecha. "El miedo tiene que cambiar de bando" o "solo el pueblo puede cambiar las cosas" se presenta como discurso populista de izquierda para superar la parálisis tanto de la socialdemocriacia como la de las izquierdas comunistas y extraparlamentarias. Alimentando la "perspectiva destituyente-constituyente" ya iniciada por el 15M, también se alimenta 
una revisión epocal al conectar con la propuesta de "ruptura democrática" de la generación derrotada por los consensos conservadores de la "transición por transacción" (Andrade, 2012). También en el contexto de la crisis Europea agravada por la llamada "política austericida de la Troika" vuelve a hablarse de conceptos como "soberanía popular" y "soberanía nacional", devaluados por la globalización neoliberal y, desde la dictadura, se empieza a disputar un "discurso patriota" en manos de la derecha.

\section{Las primeras cifras de Podemos en las redes sociales}

Este artículo se centra en el surgimiento de Podemos y como amplía su presencia en redes sociales en sus primeras diez semanas de existencia (del 17 enero al 31 de marzo de 2014). Este período inicial es de importancia no solo por el éxito que alcanzó la formación en dichas elecciones; también es la primera vez que un partido político desarrolló una campaña de difusión exitosa en redes sociales, donde la "campaña convencional" sería el complemento en términos de asignación de recursos. En esta línea, el trabajo de campo realizado se basa en tres conjuntos de preguntas que guían el relato del posicionamiento y difusión de la formación política.

En el primero se agrupan las referidas a las características sociodemográficas de las personas que se sumaron y difundieron los mensajes de Podemos en estas primeras semanas. Se dirigen a conocer quiénes son los seguidores de Podemos en Facebook, analizar sus rasgos generacionales específicos y su distribución geográfica con el objetivo de analizar la circulación del discurso que proponía vehiculizar esta formación política. Para ello se ha recurrido a los datos de seguidores de Podemos en Facebook y se los ha comparado con los datos de la población general de la red social y de España.

En segundo lugar se plantean algunas preguntas comparadas, ¿cuál es el uso y difusión alcanzado por Podemos en sus inicios, en comparación con el resto de formaciones políticas?, ¿cuál ha sido el impacto y extensión alcanzado de sus líderes políticos? Estos datos brindan una visión sobre la evolución y capacidad de difusión de los mensajes de cada líder y su formación política. Pero, además, permite visibilizar las distintas estrategias de comunicación, en la medida que un mayor número de interacciones e impacto en redes sociales se relaciona con el tipo de estrategia de comunicación desarrollada. Para este conjunto de preguntas se utilizaron las métricas disponibles públicamente a través de los respectivos perfiles de Facebook y Twitter.

Finalmente, ¿cómo se representa en el discurso de Podemos el reciente clima de movilización contra la crisis económica y política visible desde el 15M de 2011?, ¿qué lectura realiza de la coyuntura política esta joven fuerza política para confrontar la "alianza político-mediática hegemónica” desde la Transición (VVAA, 2012; Jerez, Sampedro Blanco, López Rey, 2008)? Esta progresión de la visibilidad de Podemos en las redes sociales no puede ser entendida sin analizar cómo su discurso político ha ganado atención pública de amplios sectores de población, al mismo tiempo que proponía trabajar con nuevas metodologías y herramientas políticas. Como se ha apuntado, el propio discurso tecnófilo que en los movimientos sociales supo aprovechar la lógica colaborativa y horizontal de la red, facilitó el tránsito a la forma partido (Romanos, Sadaba, 2015). Analizar las cinco publicaciones con mayor impacto en 
Facebook, de muy distinto contenido, permite acercarnos a una comprensión de la posición discursiva de Podemos atendiendo a los intereses de su público en redes sociales.

\section{Aproximación sociodemográfica}

Sin perder de vista que $15 \mathrm{M}$ ya se organizó, difundió y comunicó, fundamentalmente a través de internet (Haro Barba, Sampedro Blanco, 15 dic. 2011), el surgimiento de Podemos con un claro discurso de regeneración democrática, mantiene un perfil generacional predominantemente joven. Una primera aproximación puede verse en el Gráfico 1, donde se comparan los seguidores de Podemos con el total de usuarios de Facebook por franjas de edad y sexo. Se puede observar cómo esta atención e interés se repartió de manera similar entre hombres y mujeres (con leve seguimiento superior masculino), ubicados mayoritariamente en la franja de edad comprendida entre los 25 y 54 años.

Gráfico 1: Comparación de usuarios y seguidores de Podemos en Facebook

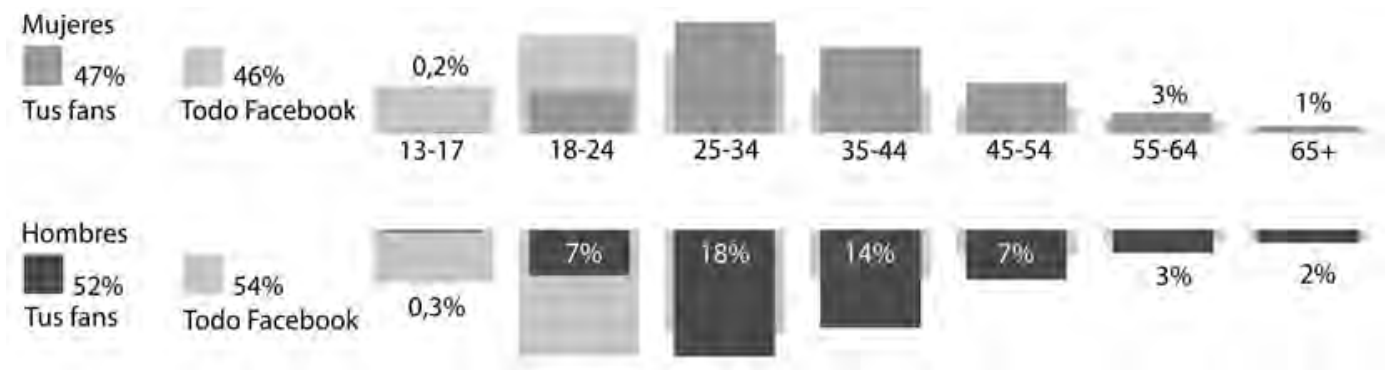

Fuente: Perfil de Podemos en Facebook. Acceso en: 31 mar. 2014.

Este gráfico muestra que los tramos de edad más interesados por el discurso de Podemos fueron los que vieron más afectadas sus expectativas laborales y vitales con las distintas políticas de "austeridad neoliberal aplicadas en la última década" como única resolución posible de la crisis. Un acceso a los recursos para la vida adulta, cada vez más difícil para unas generaciones que perciben biográficamente las dificultades de consolidar trayectorias profesionales y estabilizar su independencia definitiva del núcleo familiar. Un poco más allá, el imaginario del bienestar socialdemócrata se desvanece para una mayoría de jóvenes que constatan que vivirán peor que sus padres. En este sentido, el factor generacional clásico, ligado a la quiebra de expectativas como componente clave del ciclo de movilización contra la crisis, también puede ser una variable relevante para explicar la emergencia de una formación partidaria como Podemos para enfrentarla (Biagini, 2012; Natanson, 2012).

El menor interés por la política que se observó entre los jóvenes seguidores de Podemos en Facebook (menores de 18 y hasta los 24 años), puede relativizarse si los comparamos con la población general en su conjunto. La Tabla 1 muestra que el público de Podemos en redes sociales fue, en estos primeros meses de existencia, predominantemente joven, sobre todo del grupo entre los 25 y 34 años y con pequeñas variaciones entre ambos sexos.

La vocación de fuerza política de ámbito estatal que Podemos, originada en Madrid, mostró desde el primer momento no pudo evitar en sus redes un "desarrollo territorial" desigual, 
acorde a una sociedad plurinacional como la española. En las llamadas "regiones históricas" (Catalunya, Euskadi y Galizia) existen subsistemas políticos pluripartidistas donde terceros partidos tienen probabilidades de generar gobiernos alternativos al bipartidismo predominante en el resto del estado. Si bien el hecho de haber concurrido por primera vez a unas elecciones europeas, con circunscripción única, pudo haber supuesto una ventaja: Podemos no tuvo el mismo margen político para promover su discurso crítico-reformista en estas regiones. La Tabla 2 pone esto de manifiesto, mostrando los porcentajes de seguidores de Podemos por comunidad autónoma en comparación con la población general.

Tabla 1: Población general y seguidores de Podemos en Facebook

\begin{tabular}{l|c|r|r|r|r|r}
\hline & \multicolumn{3}{|c|}{ Población } & \multicolumn{2}{l|}{ Podemos } & \multicolumn{2}{l}{ Diferencia } \\
\hline Edad & Hombres & Mujeres & Hombres & Mujeres & Hombres & Mujeres \\
\hline $13-17$ & $2,7 \%$ & $2,6 \%$ & $0,3 \%$ & $0,2 \%$ & $-2,43 \%$ & $-2,38 \%$ \\
$18-24$ & $4,2 \%$ & $4,0 \%$ & $7,0 \%$ & $6,0 \%$ & $2,81 \%$ & $1,97 \%$ \\
$25-34$ & $8,2 \%$ & $8,0 \%$ & $18,0 \%$ & $16,0 \%$ & $9,78 \%$ & $7,96 \%$ \\
$35-44$ & $10,0 \%$ & $9,6 \%$ & $14,0 \%$ & $12,0 \%$ & $3,97 \%$ & $2,45 \%$ \\
$45-54$ & $8,6 \%$ & $8,6 \%$ & $7,0 \%$ & $7,0 \%$ & $-1,60 \%$ & $-1,56 \%$ \\
$55-64$ & $6,4 \%$ & $6,7 \%$ & $3,0 \%$ & $3,0 \%$ & $-3,40 \%$ & $-3,68 \%$ \\
$65+$ & $8,7 \%$ & $11,7 \%$ & $2,0 \%$ & $1,0 \%$ & $-6,74 \%$ & $-10,66 \%$ \\
\hline Total & $48,9 \%$ & $51,1 \%$ & $51,3 \%$ & $45,2 \%$ & $2,39 \%$ & $-5,89 \%$ \\
\hline
\end{tabular}

Fuente: Instituto Nacional de Estadística y elaboración de los autores a partir de las estadísticas de Facebook. Acceso en: 31 mar. 2014.

Tabla 2: Población y seguidores de Podemos por comunidad autónoma

\begin{tabular}{lrrrr}
\hline Comunidad autónoma & Podemos & Población & Diferencia \\
\hline Andalucía & $19,25 \%$ & $18,00 \%$ & $1,24 \%$ \\
Aragón & $4,21 \%$ & $2,86 \%$ & $1,34 \%$ \\
Asturias & $2,83 \%$ & $2,28 \%$ & $0,55 \%$ \\
Baleares & $2,72 \%$ & $2,39 \%$ & $0,33 \%$ \\
Canarias & $4,24 \%$ & $4,53 \%$ & $-0,29 \%$ \\
Cantabria & $0,91 \%$ & $1,26 \%$ & $-0,35 \%$ \\
Castilla y León & $4,16 \%$ & $5,38 \%$ & $-1,22 \%$ \\
Castilla-La Mancha & $1,41 \%$ & $4,47 \%$ & $-3,06 \%$ \\
Cataluña & $8,69 \%$ & $15,99 \%$ & $-7,30 \%$ \\
Comunidad Valenciana & $10,57 \%$ & $10,66 \%$ & $-0,09 \%$ \\
Euskadi & $2,69 \%$ & $4,66 \%$ & $-1,97 \%$ \\
Extremadura & $1,33 \%$ & $2,36 \%$ & $-1,03 \%$ \\
Galicia & $6,59 \%$ & $5,91 \%$ & $0,68 \%$ \\
Madrid & $27,41 \%$ & $13,71 \%$ & $13,71 \%$ \\
Murcia & $2,27 \%$ & $3,14 \%$ & $-0,87 \%$ \\
Navarra & $0,74 \%$ & $1,37 \%$ & $-0,63 \%$ \\
\hline
\end{tabular}

Fuente: Instituto Nacional de Estadística y elaboración de los autores. Accesos en: 26 mar. 2014; 31 mar. 2014; 1 jul. 2013. 
Madrid, ciudad donde surge el núcleo de personas que impulsan el proyecto, contaba en aquel momento con la mayor diferencia entre la población y el porcentaje de seguidores (un 13,71\%). En el otro extremo, Cataluña y Euskadi, dos comunidades autónomas con fuertes procesos nacionalistas, figuran entre las tres en las que la diferencia era mayor en términos negativos $(7,3 \%$ y $1,97 \%$ respectivamente).

\section{Partidos políticos y líderes de opinión en Facebook y Twitter}

El primer uso intensivo de las redes sociales en campañas políticas puede ser encontrado en la elección presidencial de Barack Obama en 2008. Desde ese momento las redes sociales parecen reafirmarse también como un espacio político cada vez más importante para el intercambio entre partidos, movimientos sociales y diferentes tejidos de la sociedad civil. Un espacio donde se amplifican sus reivindicaciones, adquieren visibilidad como actores y lanzan iniciativas de nuevas formas de hacer política en red. En España, hasta las elecciones europeas del mes de mayo de 2014, los partidos políticos tradicionales se mostraron cautos y con estrategias limitadas en este nuevo espacio de comunicación política, que sigue orientando la selección de candidatos en virtud de los capitales mediáticos televisivos convencionales (Sampedro Blanco, 2011). Siguiendo el rastro del poder movilizador de las redes sociales en el movimiento de protesta global contra la crisis que conecta primavera árabe, el 15M, la plaza Syntagma o Occupy Wall Street (Castells, 2012) se puede constatar que fue en estas elecciones europeas, de mayo de 2014, cuando en España comenzó a producirse la adaptación al plano electoral de estos nuevos repertorios tecnopolíticos de acción colectiva.

A partir de entonces, las redes sociales han ido ganando importancia como plataformas intermediarias en la conformación de las agendas político-mediáticas, que dejan de estar exclusivamente moldeadas por los medios de comunicación convencionales y partidos tradicionales. Con menos recursos, pero con un innovador discurso antagonista, la comunicación político-electoral a través de internet fuerza reacomodos en una disputa discursiva antes hegemonizada por la comunicación unidireccional televisiva. En esta misma línea, ya se apuntó la novedad del Movimiento 5 Estrellas de Beppe Grillo en Italia (Marco, Robles, 2011) y la aparición de los partidos piratas como iniciativas políticas que tienen en internet su vehículo de comunicación predominante.

En el caso de Pablo Iglesias y la política de redes sociales de Podemos, a lo largo de los primeros meses de la formación, se produjo una simbiosis entre una agenda propia, orientada hacia una campaña electoral - con objetivos endógenos de financiación y de estructuración de la organización en el territorio - junto con la comunicación y traducción de los principales problemas de la ciudadanía española hacia una retórica política. Su éxito se manifestó en la alta velocidad de crecimiento en redes sociales y los fenómenos virales abiertos en los primeros noventa días de vida de esta formación. El Gráfico 2 muestra la cantidad de seguidores que tienen los partidos políticos en las dos redes analizadas, Facebook y Twitter.

Estos datos permiten constatar las diferentes estrategias e intensidades de uso de estas herramientas tecnopolíticos en los diferentes partidos y candidatos. Sin duda, el grado de institucionalización y los compromisos en la política mediática tradicional de los partidos tradicionales, les llevaba a usar las redes de manera complementaria a su estrategia de 
marketing político convencional. Son los nuevos partidos, con candidatos más jóvenes y alejados de la política tradicional, los que promovieron dinámicas de conversación más horizontales, participativas y descentralizadas que les permitieron aprovechar la velocidad y viralidad para intervenir en los asuntos de actualidad desde las diferentes redes tecnosociales. Twitter, con su capacidad de agregar y distribuir mensajes, creando estados de opinión en lapsos de tiempos muy cortos, con creciente capacidad de llamar la atención de los medios de comunicación, sirve para marcar posicionamientos breves y asertivos. Facebook, con una comunidad de usuarios muchos más amplia, con un sistema de interacciones acumulativo y con períodos de latencia más sostenidos a lo largo del tiempo, permite manejar mensajes con más información e intercambiar comentarios más largos.

Gráfico 2: Cantidad de seguidores(as) por partidos políticos

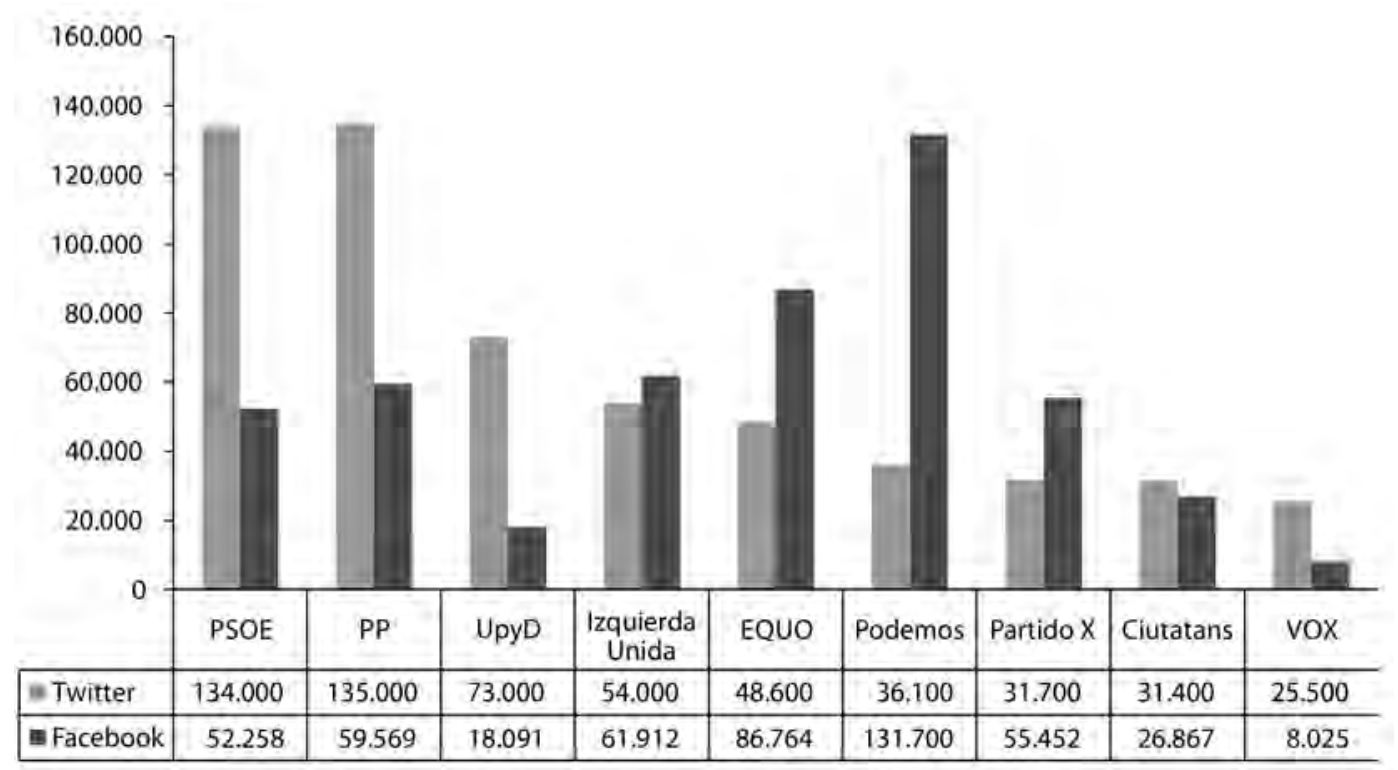

Fuente: Elaborado por los autores a partir de datos públicos de Facebook y Twitter. Acceso en: 31 mar. 2014.

El uso combinado de ambos canales, mutuamente potenciados, en el caso de Podemos ha significado un veloz crecimiento de la visibilidad y conocimiento público, sobre todo del candidato, pero también de la nueva formación. El Gráfico 3, que presenta las cifras de seguidores de los principales líderes de los partidos políticos, permite constatar la singularidad de la progresión del crecimiento del líder Pablo Iglesias y Podemos, que en noventa días de existencia de la formación tomó una clara primera posición en las redes sociales. En menor medida, en otras formaciones recientes y nuevas como Equo (Marcellesi) y el Partido X (Falciani) también se constató un aprovechamiento más intensivo de internet que el de las grandes formaciones del bipartidismo (PSOE-PP).

Una vez más el componente generacional es visible, solo la candidata socialista Elena Valenciano (nacida en 1960) parece tener una especial relevancia como creadora de opinión en la red: sus 20.354 seguidores la conformaban como la segunda candidata con más fuerza en Twitter. Ninguno de los candidatos que nació antes del año 1955 hacía un uso 


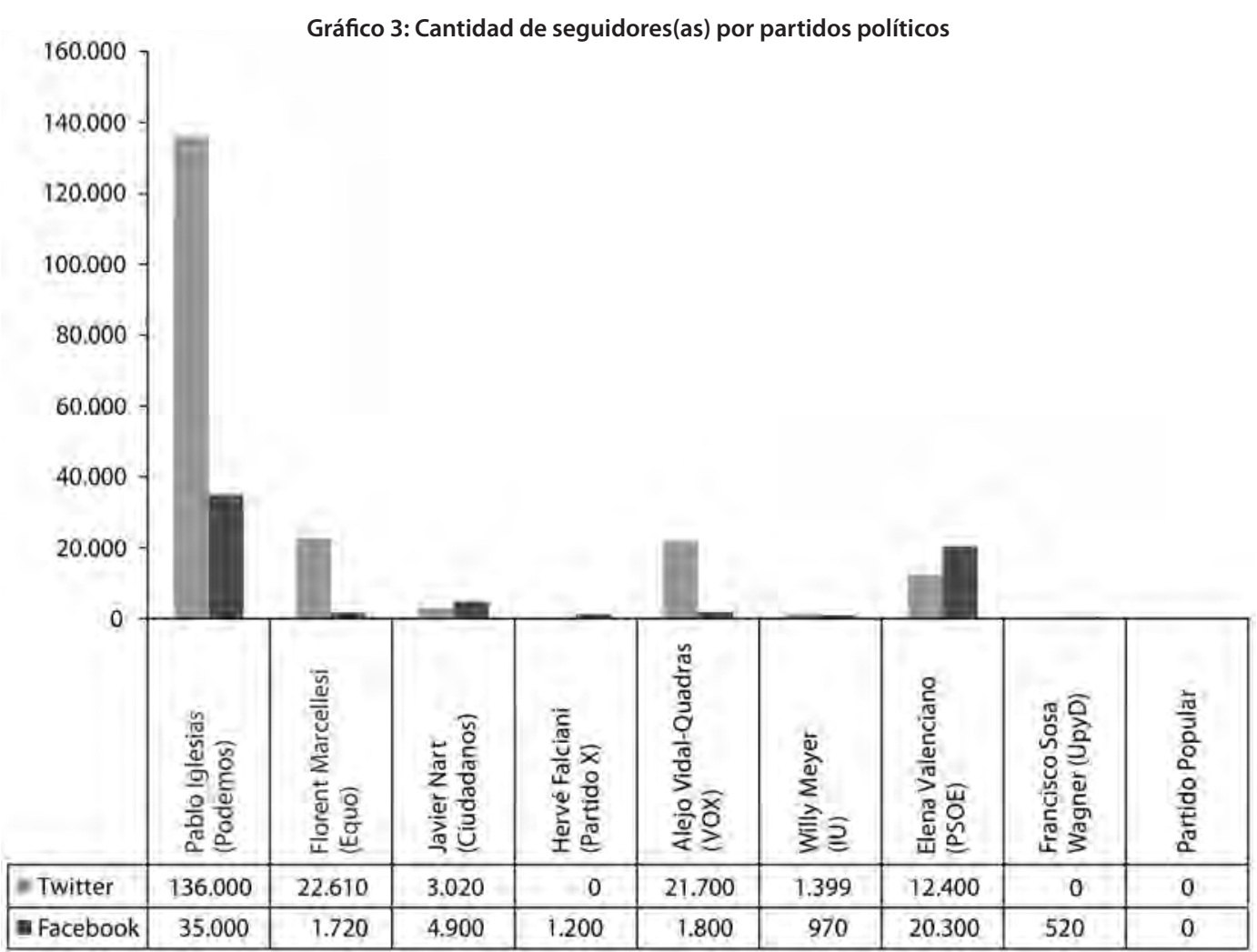

Fuente: Elaborado por los autores a partir de datos públicos de Facebook y Twitter. Acceso en: 31 mar. 2014.

efectivo de las redes sociales: Vidal-Quadras, de Vox; Sosa Wagner, de Unión Progreso y Democracia; Meyer, de Izquierda Unida; Nart, de Ciudadanos, o Miguel Arias, Cañete del Partido Popular, se vieron "obligados" a abrir o relanzar cuentas en Twitter para la campaña electoral europea.

Al contrario de los concurrentes nóveles, los partidos tradicionales siguieron apostando por la "elección de candidatos" según el tradicional reconocimiento mediático televisivo de cargos y trayectorias políticas de liderazgos de segunda fila, y en cierta medida despreciaron la potencialidad de la "política de proximidad" que puede activarse en las redes sociales para potenciar el diálogo o una cierta rendición de cuentas.

En los primeros noventa días existencia, la página de Podemos en Facebook tuvo, de media, unas 120 mil visitas diarias, con una progresión de crecimiento desconocida hasta el momento entre las fuerzas políticas en España, que le llevó en este periodo a acumular 131.700 seguidores. Solo comparable con la velocidad de crecimiento de seguidores de un movimiento social de congregación indignada del 15M, en la misma línea de lo expuesto por Toret (2015).

\section{El proceso de enmarcamiento en redes sociales}

Si analizamos la actividad de las redes sociales de Podemos para el período analizado, encontraremos que las publicaciones pueden agruparse en torno a: (1) promoción de actos de 
campaña; (2) petición de fondos para sufragar la campaña electoral por medio de crowdfunding o venta de merchandising; (3) artículos de prensa en los que se hace referencia a Podemos; (4) apariciones de Pablo Iglesias y otros candidatos en televisiones; (5) promoción de los elementos centrales del ideario de Podemos; y (6) comentarios alineados en una estrategia de visibilización de los movimientos sociales históricos y actuales.

De hecho, se constata que las publicaciones que más impacto han tenido en la comunidad de Facebook, no son las que hablan propiamente de Podemos, sino aquellas que conmemoran luchas sociales históricas o apoyan las movilizaciones en curso en la agenda política española. El resto de publicaciones tienen visibilidad y relevancia política, pero no alcanzan las cotas de viralidad de las dedicadas a los movimientos sociales que contaban - y cuentan - con simpatías ampliamente extendidas entre la población. Si la publicación media de Podemos en Facebook llegó a treinta mil personas, el efecto viral de los casos aquí analizados llegan a multiplicar su alcance hasta diez veces.

La Imagen 1 es la publicación con mayor impacto del período analizado, correspondiente al 27 de marzo de 2014. Puede observarse cómo el "marco político indignado" sirve para trazar una divisoria en el campo político, con una noticia referida al fallecimiento de un niño dependiente a quien el gobierno autonómico reclamaba el pago de facturas atrasadas para continuar con el tratamiento. Su comentario final es clarificador en este sentido: "Porque ya basta de que la ciudadanía tenga que mendigar que los recursos de todos se inviertan en salud, cuidado y educación. Una vida digna es un derecho. Una clase política como la actual, una vergüenza".

Trazar discursivamente esta divisoria entre la mayoría que ve menguar sus recursos y derechos con la implementación de las políticas de austeridad y la minoría "corrupta" que las aplica al tiempo que privatiza y cobra "sobres" (comisiones) ha tenido un enorme impacto en términos de "pedagogía política de la indignación". La retórica de Podemos se demostró efectiva estableciendo un antagonismo identitario entre un nosotros/ellos, interpelando a las élites con un discurso plebeyo que les recrimina ser "casta", "mafia" o "golfos", al tiempo que su principal eslogan anunciaba "Es la hora de la gente".



Fallece el niño dependiente a quien el Gobierno de Cospedal exígía facturas para pagar sus...

El recurso de alzada llegó tarde (ver documento). Jomian Leonel, de 13 años de edad, fallecí en cuenca este miércoles a consecuencia de las graves...

EL PLURAL.
308608 Personas a las que se aicanź

9386 the gusta, comentanos y comtenido compantido

$\begin{array}{lll}4349 & 1277 & 3072\end{array}$

Me gusta En la pubicación En el contenido
compartido

$\begin{array}{lll}1682 & 144 & 1538\end{array}$

En la publicadión
Enentanios contenidd
compartido

\begin{tabular}{l|l|l}
3355 & 3198 & 157
\end{tabular}

$\begin{array}{lll}\text { Veces que se } & \text { En la publicaoón } & 157 \\ \text { Compartio contenidd } & \text { Eompantido } \\ \text { compan }\end{array}$

20561 clics en publicaciones

\begin{tabular}{l|l|l}
0 & 10506 & 10055
\end{tabular}



COMENTARIOS NEGATIVOS

0 Ocuitar publicadón $\quad 0$ ocultar todas las

publicadiones

O Repontar como correo no 2 Ya no me gusta esta página deseado
Imagen 1: Primera publicación más vista en Facebook 
Tres de las publicaciones más viralizadas entre los seguidores de Podemos en Facebook están centradas en la fecha de movilización más relevante que tuvo lugar en la primavera de 2014: las Marchas de la Dignidad del 22M. ${ }^{10}$ Fueron marchas de largo recorrido, con cientos de personas que atravesaron todo el territorio nacional, que accedieron simultáneamente por las seis principales autopistas a la capital de España y que convocaron a más de un millón de ciudadanos en la manifestación de apoyo. A pesar de la magnitud de la protesta, el tratamiento recibido por los medios de comunicación fue exiguo y nulo el atendimiento por parte del gobierno. El mismo 22 de marzo, por la mañana, Podemos publica en su perfil de Facebook: "Las calles de Madrid comienzan a llenarse. Han sido muchas horas de viajes y caminatas, pero entre los rostros de cansancio se empieza a despertar la alegría de la lucha compartida. Hoy no hay tregua, hemos perdido el miedo y miles de rostros anónimos caminamos paso a paso reivindicando nuestros derechos".

El elemento viral reposa, en este caso, en la identificación de un nosotros "anónimo", con lo que se producen vinculaciones de significado en torno a la idea de pueblo, aunque también con resonancias en torno al movimiento tecnociudadanista Anonymous, presente icónicamente en el 15M y en la última ola de contestación a la globalización conservadora. Al día siguiente, en el perfil de Podemos en Facebook se comentan los episodios de violencia acaecidos en la manifestación, cuando ésta no había sido clausurada por los organizadores, todavía con oradores presentes en el palco: “¿Qué es la dignidad popular? Ayer por la noche, al final de las \#Marchas, mientras los antidisturbios cargaban, la orquesta Solfónica ${ }^{11}$ no dudó en seguir tocando. Y mientras los antidisturbios lanzaban gas lacrimógeno, siguieron tocando. Sencillamente gracias".

El seguimiento de estas publicaciones superaron ampliamente las cien mil personas. Podemos no dudó en entrar en la disputa interpretativa de esta movilización, con una publicación el 24 de marzo, que mostrara una gráfica difundida por la organización de las marchas que cuestionaban las cifras policiales de asistencia a la manifestación. También contra el enmarcamiento de los principales medios de comunicación que eludían hablar de

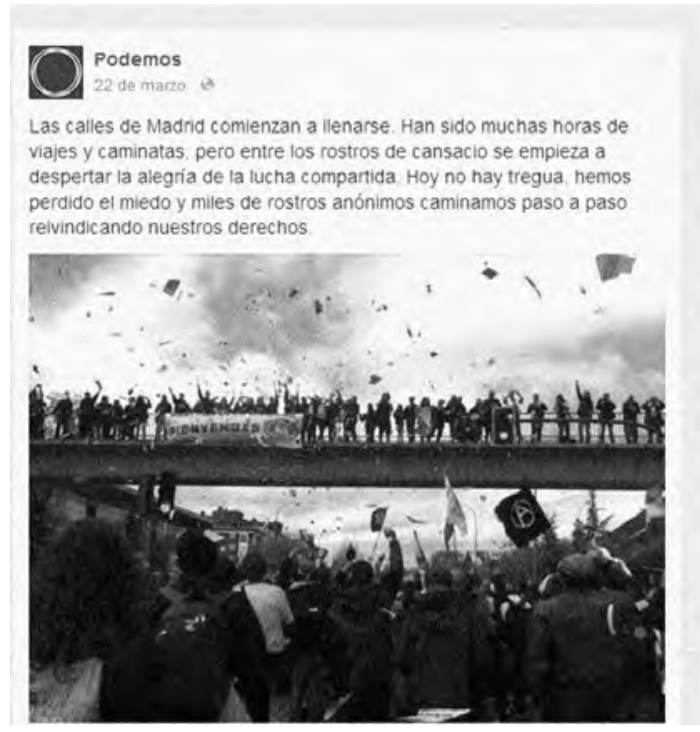

Imagen 2:

Segunda publicación más vista en Facebook 
su masividad e insistían en otorgar el protagonismo de la jornada a los enfrentamientos entre policía y manifestantes. Podemos acusó la voluntad de la Delegación de Gobierno (responsable político-policial) de convertir la masiva jornada de movilización en un problema de "orden público", cuando una mayoría social protesta reclamando "pan, trabajo y techo" (eslogan de la Coordinadora 22M).

Tabla 3: Impacto de la segunda publicación más vista en Facebook, correspondientes a la Imagen 2

\begin{tabular}{|c|c|c|}
\hline \multicolumn{3}{|c|}{ 148.864 Personas a las que alcanzó } \\
\hline \multicolumn{3}{|c|}{ 12.039 Me gusta, comentarios, y contenido compartido } \\
\hline 9.621 & 5.944 & 3.677 \\
\hline Me gusta & En la publicación & En el contenido compartido \\
\hline 432 & 200 & 232 \\
\hline Me gusta & En la publicación & En el contenido compartido \\
\hline 1.968 & 1.881 & 105 \\
\hline $\begin{array}{l}\text { Veces que se } \\
\text { compartió }\end{array}$ & En la publicación & En el contenido compartido \\
\hline \multicolumn{3}{|c|}{ 6.795 Clics en publicaciones } \\
\hline 4.694 & 21 & 2.080 \\
\hline $\begin{array}{l}\text { Visualizaciones de } \\
\text { fotos }\end{array}$ & Clics en el enlace & Otros clics \\
\hline \multicolumn{3}{|c|}{ COMENTARIOS NEGATIVOS } \\
\hline 0 Ocultar publicación & & 0 Ocultar todas las publicaciones \\
\hline $\begin{array}{l}\text { o Reportar como } \\
\text { correo no deseado }\end{array}$ & & 0 Ya no me gusta esta página \\
\hline
\end{tabular}

Fuente: Perfil de Podemos en Facebook. Acceso en: 31 mar. 2014.

Las cifras de asistencia al $\# 22 \mathrm{M}$ que han facilitado muchos "medios serios" son un ejemplo de que hace falta un cambio también en el periodismo

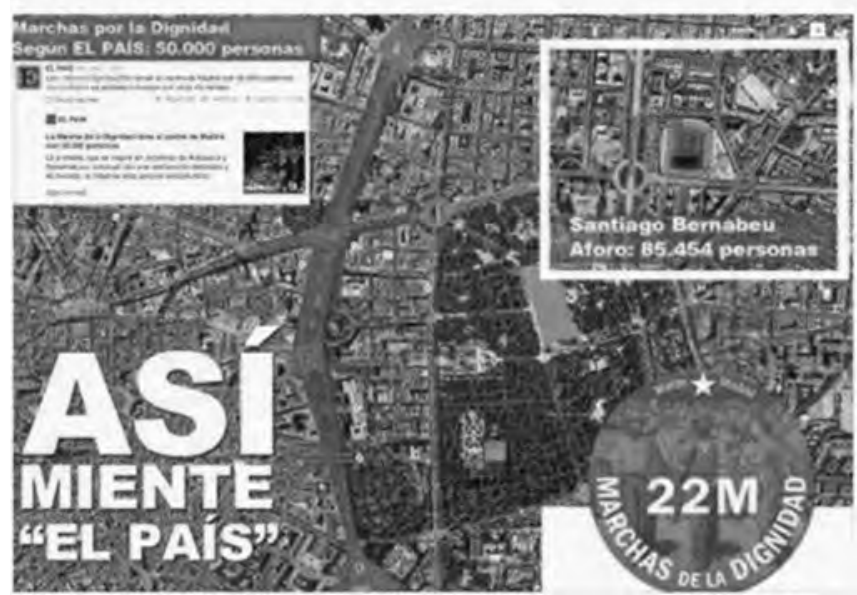

Imagen 3:

Cuarta

publicación más vista en

Facebook 
Tabla 4: Impacto de la cuarta publicación más vista en Facebook, correspondiente a la Imagen 3

\begin{tabular}{|c|c|c|}
\hline \multicolumn{3}{|c|}{ 137.216 Personas a las que alcanzó } \\
\hline \multicolumn{3}{|c|}{ 7.608 Me gusta, comentarios, y contenido compartido } \\
\hline 4.912 & 2.564 & 2.348 \\
\hline Me gusta & En la publicación & En el contenido compartido \\
\hline 454 & 134 & 320 \\
\hline Me gusta & En la publicación & En el contenido compartido \\
\hline 2.242 & 2.150 & 92 \\
\hline Veces que se compartió & En la publicación & En el contenido compartido \\
\hline \multicolumn{3}{|c|}{ 26.002 Clics en publicaciones } \\
\hline 14.720 & 17 & 11.265 \\
\hline Visualizaciones de fotos & Clics en el enlace & Otros clics \\
\hline \multicolumn{3}{|c|}{ COMENTARIOS NEGATIVOS } \\
\hline 0 Ocultar Publicación & & 0 Ocultar todas las publicaciones \\
\hline $\begin{array}{l}0 \text { Reportar como correo } \\
\text { no deseado }\end{array}$ & & 2 Ya no me gusta esta página \\
\hline
\end{tabular}

Fuente: Perfil de Podemos en Facebook. Acesso en: 31 mar. 2014.

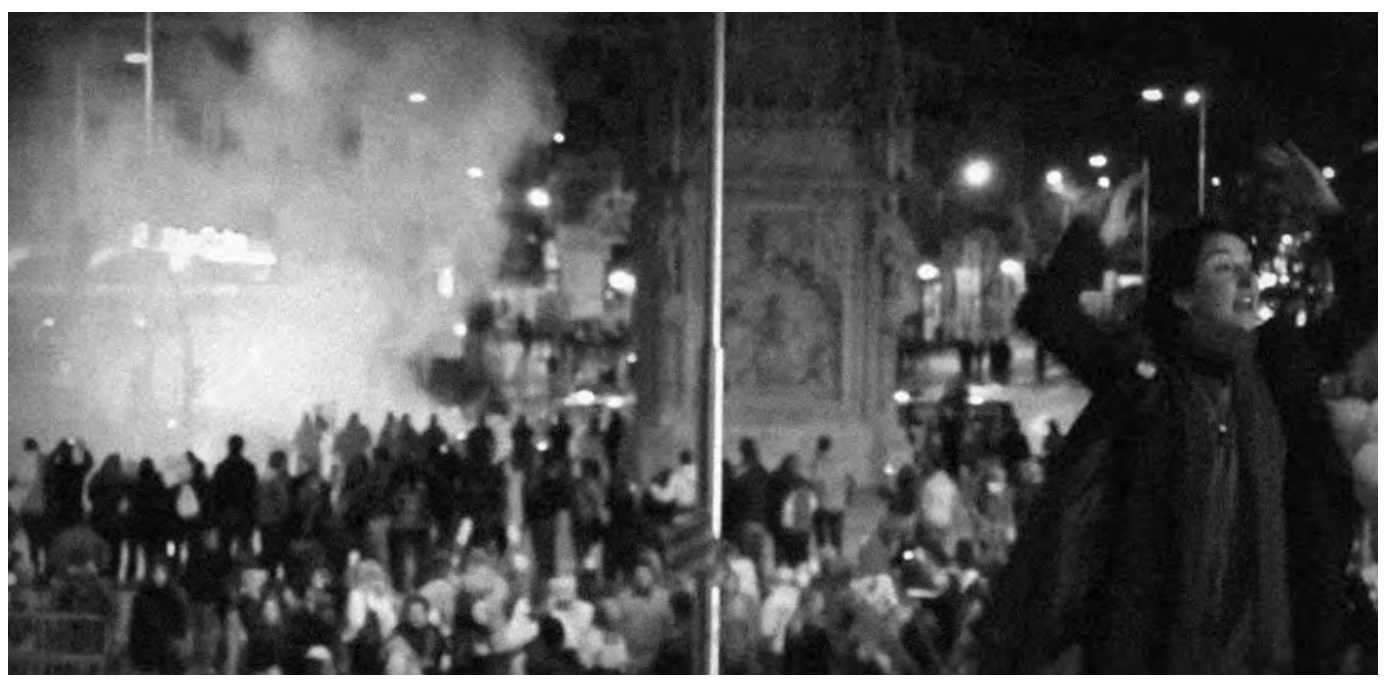

Imagen 4: Quinta publicación más vista en Facebook

Es interesante constatar cómo la publicación de Podemos del 8 de Marzo, día de la mujer trabajadora, mero recuerdo conmemorativo de la huelga textil de 1857 que le da origen, tuvo un importante impacto viral. Sin duda, se relaciona con el tenso contexto que enfrenta el movimiento feminista ante el histórico retroceso que en esas fechas se produjo con la propuesta de reforma ultraconservadora de la Ley del aborto, posteriormente abandonada por el gobierno en virtud del descontento popular y la completa falta de apoyo de los demás partidos políticos, incluida la mayoría de su electorado conservador. Muchas voces de la opinión pública interpretaron que la agresiva reforma de tan marcada identidad ideológicoreligiosa operaba como "cortina de humo" sobre la crisis económica. 
Tabla 5: Impacto de la quinta publicación más vista en Facebook, correspondiente a la Imagen 4

\begin{tabular}{|c|c|c|}
\hline \multicolumn{3}{|c|}{ 115.904 Personas a las que alcanzó } \\
\hline \multicolumn{3}{|c|}{ 6.269 Me gusta, comentarios, y contenido compartido } \\
\hline 4.445 & 2.408 & 2.047 \\
\hline Me gusta & En la publicación & En el contenido compartido \\
\hline 398 & 171 & 227 \\
\hline Me gusta & En la publicación & En el contenido compartido \\
\hline 1.416 & 1.315 & 101 \\
\hline Veces que se compartió & En la publicación & En el contenido compartido \\
\hline \multicolumn{3}{|c|}{ 18.350 Clics en publicaciones } \\
\hline 6.624 & 983 & 10.7435 \\
\hline Visualizaciones de fotos & Clics en el enlace & Otros clics \\
\hline \multicolumn{3}{|l|}{ COMENTARIOS NEGATIVOS } \\
\hline 0 Ocultar publicación & & 0 Ocultar todas las publicaciones \\
\hline $\begin{array}{l}\text { 0 Reportar como correo } \\
\text { no deseado }\end{array}$ & & 4 Ya no me gusta esta página \\
\hline
\end{tabular}

Fuente: Perfil de Podemos en Facebook. Acceso en: 31 mar. 2014.

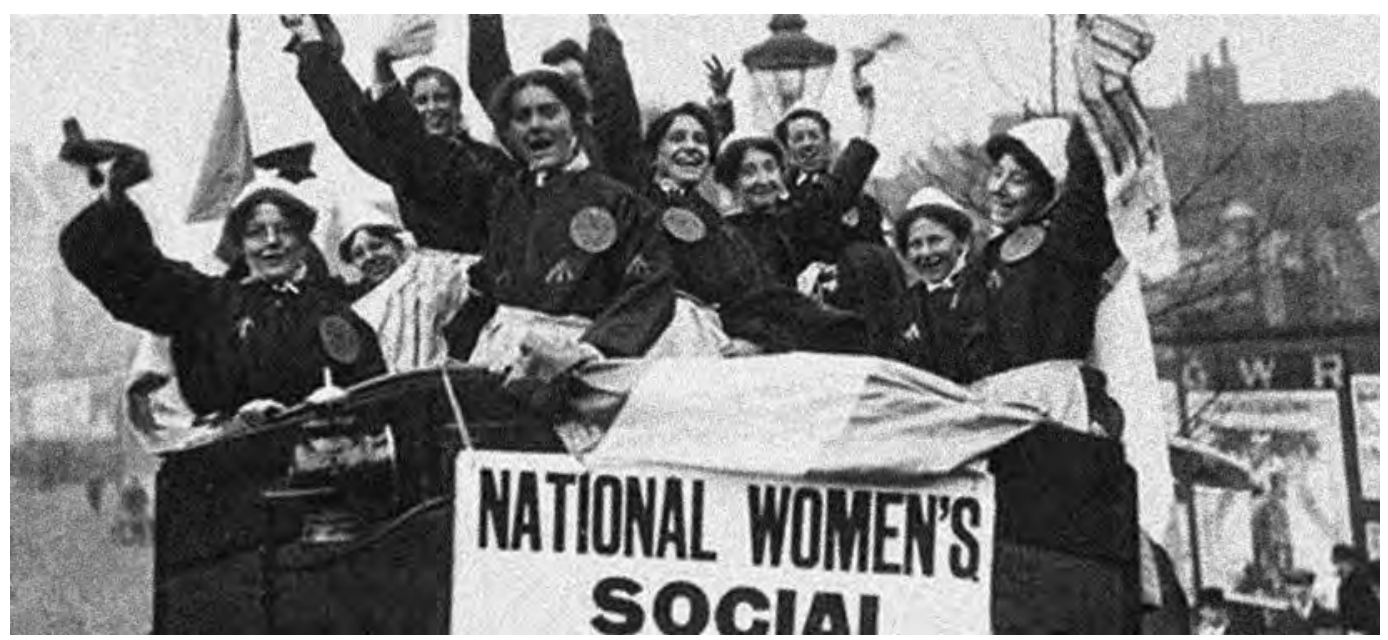

Imagen 5: Tercera publicación más vista en Facebook

Dado que Podemos es un partido que se dio a conocer fundamentalmente a través de las redes sociales, la viralidad de sus publicaciones es central a la hora de explicar el nuevo método de participación con el que se proponía incluir y movilizar al electorado. No sólo para elaborar y difundir su programa electoral, que ha sido elaborado de forma colectiva en la red, ${ }^{12}$ sino para poner en marcha herramientas de financiación de la campaña y elecciones primarias. 
Tabla 6: Impacto de la tercera publicación más vista

en Facebook, correspondiente a la Imagen 5

\begin{tabular}{|c|c|c|}
\hline \multicolumn{3}{|c|}{ 140.224 Personas a las que alcanzó } \\
\hline \multicolumn{3}{|c|}{ 10.356 Me gusta, comentarios, y contenido compartido } \\
\hline 7.492 & 2.722 & 4.770 \\
\hline Me gusta & En la publicación & En el contenido compartido \\
\hline 292 & 56 & 236 \\
\hline Me gusta & En la publicación & En el contenido compartido \\
\hline 2.572 & 2.431 & 141 \\
\hline Veces que se compartió & En la publicación & En el contenido compartido \\
\hline \multicolumn{3}{|l|}{ 4.410 Clics en publicaciones } \\
\hline 1.143 & 135 & 3.132 \\
\hline Visualizaciones de fotos & Clics en el enlace & Otros clics \\
\hline \multicolumn{3}{|l|}{ COMENTARIOS NEGATIVOS } \\
\hline 0 Ocultar publicación & & 0 Ocultar todas las publicaciones \\
\hline $\begin{array}{l}\text { 0 Reportar como correo no } \\
\text { deseado }\end{array}$ & & o Ya no me gusta esta página \\
\hline
\end{tabular}

Fuente: Perfil de Podemos en Facebook. Acceso en: 31 mar. 2014.

\section{Consideraciones finales}

Las respuestas institucionales a la crisis económica ofrecidas desde 2008 han propiciado que las demandas ciudadanas cobraran mayor visibilidad en España. Las movilizaciones del 15M pueden comprenderse como un punto de inflexión frente a las soluciones de los principales partidos en la delicada coyuntura social y nacional, percibida como ruptura de un "contrato social" y político implícito desde la llamada transición. Este panorama no es exclusivo de España, y se enmarca en una corriente de "demandas globales", democratizadoras frente a las transformaciones operadas por la globalización neoliberal de las últimas décadas (Castells, 2012), aunque ineludiblemente estas dinámicas globales se articulan con las singularidades del contexto histórico nacional.

En el caso español, este ciclo de movilización social e intelectual empieza a abrir una perspectiva crítica de las herencias autoritarias en unas esferas públicas altamente mediatizadas, que en democracia también han mantenido a la ciudadanía despolitizada. La erosión de la imagen de la "clase política" por la crisis y la corrupción ha corrido paralela al surgimiento de numerosas iniciativas y plataformas ciudadanas que buscan visibilizar sus luchas y reclamos sociales. En este marco, los nuevos partidos políticos intentan presentarse como "partidos ciudadanos", "de la gente", "nuevos", alternativos al bipartidismo (PP-PSOE) percibido como "profesional" e "integrado" a un sistema parlamentario hoy corrompido. El primer desafío real a la calculada estabilidad del sistema partidario postfranquista la realizaron candidatos sin grandes organizaciones, pero con un considerable capital mediático y social acumulado, en un coyuntura de calamitoso declive de la imagen de los grandes partidos pero que, no obstante, siguen contando con el apoyo de los grandes medios.

Los bajos presupuestos de estos nuevos partidos no les permitieron la pasividad que ha caracterizado los usos tecnopolíticos en campañas electorales de los partidos políticos 
tradicionales (Sampedro Blanco, 2011; Anduiza, 2009), tuvieron que centrar sus recursos de forma mucho más selectiva y eficiente. Teniendo en cuenta estas necesidades, el crecimiento e influencia en las personas que las utilizan, las redes sociales se convirtieron en el canal predilecto para la difusión de nuevas ideas políticas y sus campañas electorales innovadoras.

Este es el caso de Podemos, un partido político que nació buscando representar la "indignación" de los sectores más jóvenes, trabajando con éxito las redes sociales no solo como estrategia electoral, sino como plataforma de organización y con la voluntad de fomentar la participación horizontal de sus militantes. A través del análisis sociodemográfico de las personas que siguen Podemos en Facebook se han puesto de manifiesto algunos datos sobre los intereses de sus públicos afines, principalmente entre aquellos grupos de población cuyas edades son las más afectadas por las consecuencias de las políticas "austericidas" de los últimos años. Este marco es también coherente con la intención de Podemos de captar un público descontento, afín a un marco interpretativo destituyente/constituyente de regeneración política en España, ya activado por el 15M.

Pablo Iglesias, profesor universitario con dotes comunicacionales y un considerable capital mediático acumulado, logró posicionar a gran velocidad a Podemos como partido y a él como candidato en las redes sociales. Su labor televisiva en programas propios y ajenos le otorgaron una dimensión pública (con conocimiento de más del 40\% de la población) fundamental para crear una articulación sinérgica en la comunicación "multicapa" sobre la que se apoyan tanto la campaña como el propio discurrir organizativo de Podemos (Toret, 2015; Romanos, Sadaba, 2015). Su evolución demoscópica mostró una evolución a lo largo de dos meses de un primer registro de un $0,2 \%$ como respuesta espontánea, a más de un 1,7\% antes del inicio de la campaña electoral para las elecciones europeas de mayo de 2014 (y 4,5 entre los votantes menores de 35 años).

El resultado del análisis de las publicaciones con mayor impacto en Facebook nos dan dos claves discursivas fundamentales para la comprensión del intento de renovación de las coordenadas ideológicas e identitarias de Podemos en estos primeros meses de existencia. Por una parte, gran parte de sus publicaciones referían a luchas y movimientos sociales previos y existentes o a mensajes que apelaban al sentido común de la ciudadanía indignada buscando insertarlo como fuerza política en una voluntad más general de cambio no recogida en el sistema partidario. Por otra, se identificaba a la clase política como "casta", responsable de la situación y se postulaba la necesidad de que la "gente normal" en tanto "pueblo" se incorporase a la política, intentando ir más allá del tradicional eje izquierda-derecha, difícilmente legible ya en las grandes transformaciones de la globalización neoliberal apoyadas por las grandes familias conservadoras y socialdemócratas. Como ya se advertía hace más de una década y media, atrapados en la lógica de la política informacional y en los límites impuestos por la globalización al Estado-nación como espacio de gobernabilidad, hoy los partidos son más "negociadores influyentes que innovadores poderosos" (Castells, 1999, p.400). Siendo todavía mediadores fundamentales para la viabilización hacia el estado de las demandas sociales encabezadas por los movimientos sociales, su capacidad de innovación dependerá de su conciencia estrategia para construir reticulaciones compartidas para reforzarse mutuamente.

Los usos tecnopolíticos que habían dinamizado la movilización del 15M se amplían y sofistican con Podemos, pareciendo abrir una ventana de oportunidad a esta dinámica de 
experimentación entre partidos y movimientos. Los sorpresivos resultados obtenidos en su primera cita electoral (7,98\% de los votos) ayudaron a mantener la pauta previa de crecimiento celérico. Porque el discurso y el "método" Podemos contenían elementos innovadores suficientes para resignificar en el contexto de crisis las luchas de los movimientos sociales en una sociedad despolitizada y renuente al conflicto.

A modo de epílogo podemos constatarlo tras las elecciones de mayo, cuando el número de seguidores de Podemos en las redes sociales se ha multiplicado hasta ser el partido hegemónico en las dos redes sociales más importantes en España, con 976 mil seguidores en Facebook y 758 mil en Twitter (oct. 2015). Un número de seguidores mucho más grande que el de los restantes partidos, Izquierda Unida (161 mil/234 mil), Partido Popular (103 mil/378 mil) y PSOE (100 mil/297 mil), incluido el "nuevo" partido Ciudadanos (202 mil/204 mil). ${ }^{13}$ La estrategia de redes sociales de Podemos se ha revelado como central y efectiva dentro de una campaña electoral que contaba con un presupuesto muy limitado, y que ha sido capaz de conectar con la sociedad civil e interpelarla, por primera vez en España, a través de las nuevas tecnologías. Redes y aplicaciones que ha sido incorporado al método organizativo junto con herramientas como foros (Plaza Podemos, Loomio y Reddit) aplicaciones para toma de decisiones y elecciones (Appgree, Agora Voting), y un sistema de crowdfunding o sistema de microdonaciones para financiarse). Innovaciones, todas ellas, en la forma de hacer política, que parecen estar dirigidas a aumentar la participación ciudadana en la toma de decisiones políticas.

\section{NOTAS}

${ }^{1}$ El 15M fue una protesta ciudadana al calor de las "primaveras árabes", que posteriormente encontró eco en otras ciudades y países con el nombre de ocuppy. En el caso de España, comenzó en Madrid con la protesta por la detención de unos manifestantes, se convirtió en una acampada en la Puerta del Sol (un punto simbólico de la ciudad) y convocó a decenas de miles de personas a lo largo de una primavera donde la ciudadanía buscó organizarse para manifestar su profundo descontento con la situación sociopolítica que atravesaba el país (Haro Barba, Sampedro Blanco, 15 dic. 2011). Estas manifestaciones funcionaron como un catalizador de todo un conjunto de demandas ciudadanas contra los poderes políticos establecidos, y a quienes participaron en ellas se les denominó indignadas/os. Más información en: https://15mpedia.org.

${ }^{2}$ La recomposición del bipartidismo tradicional, representados por socialdemócratas (Partido Socialista Obrero Español - PSOE) y conservadores (Partido Popular - PP) puede apoyarse en dos fuerzas parlamentarias "auxiliares" por derecha e izquierda que ya ayudan a gobernar en algunas comunidades autónomas: Unión, Progreso y Democracia (UPyD) e Izquierda Unida (IU, coalición en torno al Partido Comunista de España). Los estudios demoscópicos en las crisis les anuncian un sensible crecimiento, aunque las muestras pequeñas utilizadas en el marco de la crisis dificultan la percepción de la emergencia de nuevos partidos: solo Podemos recoge intenciones de voto como para sacar escaños (entre otras cuatro nuevas propuestas que disputan la idea ciudadana: Red Ciudadana-Partido X, Movimiento RED, Ciudadanos-Partido de la Ciudadanía y Vox).

${ }^{3}$ Cabe destacar la aparición del periódico Público en 2007, que rompía el monopolio de El País como referente periodístico exclusivo durante décadas para los públicos progresistas. La aparición de nuevos diarios y revistas políticas impresas (Diagonal, La Marea, Mongolia, Tinta Libre) y nuevos periódicos y colectivos crítico de distribución on line (ElDiario.es, ElPlural; Rebelión, Sin permiso entre muchas otras vinculadas a colectivos ligados al $15 \mathrm{M}$ que las dinamizan por las redes sociales).También los programas de las distintas cadenas evidencian el cambio de ciclo de atención: los debates políticos ganan terreno porque son rentables. El candidato de Podemos, Pablo Iglesias, tiene un particular protagonismo.

${ }^{4}$ Otras alusiones polémicas presentes en el manifiesto, consideradas hirientes para la socialdemocracia del PSOE e IU, que en silencio eluden la polémica: "Nunca en Europa ha habido tanta gente descontenta con la pérdida de derechos y, al tiempo, menos perspectivas de poder canalizar esa indignación a través de alguna opción electoral que emocione ... no es cierto que estemos instalados en la derrota ... es más real 
que nunca nuestra exigencia de una mayor generosidad a los representantes, de una mayor horizontalidad y transparencia ... Hacía décadas que no era tan real nuestro deseo de tomar nuestras propias decisiones y responder a nuestras propias preguntas ... Sólo de la ciudadanía puede venir la solución". Ver en: http:// www.cuartopoder.es/alsoldelacalle/files/2014/01/Mover-ficha-convertir-la-indignacio\%CC\%81n-en-cambiopoli\%CC\%81tico.pdf.

${ }^{5}$ El sistema electoral fue uno de los grandes pactos implícitos en los acuerdos conservadores de la transición. A pesar de ser nominalmente proporcional, con circunscripciones provinciales y con la "fórmula D'Hont" en el sistema de reparto de escaños, logra una dinámica mayoritaria con sobre representación de las zonas rurales y una distorsión porcentual entre escaños y votos que ha llegado a superar el 7\% (en las generales del 2000). La lógica bipartidista PSOE-PP ha sido excluyente de terceros y cuartos partidos, salvo en Cataluña y País Vasco (y en menor medida, en Galicia) (Iglesias Turrión, Monedero, 2011).

${ }^{6}$ La labor investigadora de Pablo Iglesias atiende movimientos sociales, comunicación política y sistemas electorales (Iglesias Turrión, Nega (LCDM), 2013; Iglesias Turrión, Monedero, 2011). El profesor Monedero ha alcanzado un reconocible éxito editorial en América y en España por su reflexión sobre globalización, estado y democracia, transición española y la crisis de la izquierda (Monedero, 2011, 2012). Ver http:// es.wikipedia.org/wiki/Juan_Carlos_Monedero, http://www.comiendotierra.es/, http://es.wikipedia.org/wiki/ Pablo_Iglesias_Turri\%C3\%B3n y http://blogs.publico.es/pablo-iglesias/.

${ }^{7}$ Ver http://www.periodistadigital.com/periodismo/tv/2013/05/12/alfonso-rojo-sobre-la-marcha-a-cuba-dewilly-toledo-willy-si-bebes-no-disertes.shtml.

${ }^{8}$ Ver http://www.publico.es/487297/la-tuerka-supera-a-la-noche-en-24-horas-en-share-social y https://twitter. com/J_LoSantos/status/436134472871079936.

9 Se ha medido el "impacto" en función de las "personas alcanzadas" (en terminología de Facebook) por cada publicación y se presentan, para cada una de ellas, las métricas que se tuvieron a disposición.

${ }^{10}$ Las Marchas de la Dignidad consistieron en movilizaciones que partieron desde distintas ciudades para confluir en la capital de España, Madrid, el 22 de marzo de 2014. Conforman el ciclo de movilizaciones que se originaron en el 15M cuyas demandas se enmarcaban dentro de una dignidad ciudadana perdida, centrando su foco en la clase política en general.

${ }^{11}$ Para conocer más, ver http://solfonica.wordpress.com/.

${ }^{12}$ El programa electoral de Podemos ha sido elaborado con una Wiki Programatica colaborativa con aportaciones de los "Círculos" y ciudadanos individuales.

${ }^{13}$ Los datos presentados han sido extraídos el 7 sep. 2014.

\section{REFERENCIAS}

ALCAZAN.

Tecnopolitica, internet y r-evoluciones: sobre la centralidad de redes digitales en el \#15M. Barcelona: Icaria. 2012.

ANDRADE, Juan.

El PCE y el PSOE en (la) transición: la evolución ideológica de la izquierda durante el proceso de cambio político. Madrid: Siglo XXI de España. 2012.

ANDUIZA, Eva.

Internet, campanyes electorals i ciutadans: l'estat de la qüestió. Quaderns del CAC, n.33, p.5-12. 2009.

ANDUIZA, Eva et al.

Los usos políticos de internet en España. Revista Española de Investigaciones Sociológicas, n.129. 2010.
BIAGINI, Hugo E.

La contracultura juvenil: de la emancipación a los indignados. Buenos Aires: Capital Intelectual. 2012.

\section{CÁRITAS.}

Desigualdad y derechos sociales: análisis y perspectivas. Madrid: Cáritas; Fundación Foessa. Disponible en: http://www.caritas.es/ imagesrepository/CapitulosPublicaciones/4551/ Desigualdad\%20y\%20derechos\%20sociales.\%20 Versi\%C3\%B3n\%20digital.pdf. Acceso en: 7 dic. 2015. 2013.

CASTELLS, Manuel.

Redes de indignación y esperanza: los movimientos sociales en la era de internet. Madrid: Alianza. 2012.

CASTELLS, Manuel.

Comunicación y poder. Madrid: Alianza. 2009. 
CASTELLS, Manuel.

La era de la información: economía, sociedad y cultura. t.2: El poder de la identidad. Buenos Aires: Siglo XXI. 1999.

CURRAN, James.

Medios de comunicación y poder en una sociedad democrática. Barcelona: Hacer. 2005.

DELLA PORTA, Donatella; DIANI, Marco. Los movimientos sociales. Madrid: Editorial Complutense; Centro de Investigaciones Sociológicas. 2011.

FERNÁNDEZ-SAVATER, Amador. El $15 \mathrm{M}$ y la crisis de la cultura consensual en España. Periférica, n.13, p.63-71. 2012.

FRASER, Nancy.

Iustitia interrupta: reflexiones críticas desde la posición "postsocialista". Santa Fé de Bogotá: Siglo del Hobre; Universidad de los Andes.1997.

HABERMAS, Jürgen.

Historia y crítica de la opinión pública: la transformación estructural de la vida pública. Barcelona: Gustavo Gili. 1981.

HARO BARBA, Carmen; SAMPEDRO BLANCO, Victor.

Activismo político en red: del Movimiento por la Vivienda Digna al 15M. Teknokultura, v.8, n.2, p.157-175. Disponible en: http://teknokultura. net/index.php/tk/article/view/14. Acceso en: 7 dic. 2015. 15 dic. 2011.

IGLESIAS TURRIÓN, Pablo; MONEDERO, Juan Carlos.

¡Qué no nos representan! El debate sobre el sistema electoral español. Madrid: Editorial Popular. 2011.

IGLESIAS TURRIÓN, Pablo; NEGA (LCDM). ¡Abajo el régimen! Conversación entre Pablo Iglesias y Nega (LCDM). Barcelona: Icaria. 2013.

INURRIETA, Alejandro et al.

Qué hacemos por la vivienda. Madrid: Akal. 2014.

JEREZ, Ariel; SAMPEDRO BLANCO, Víctor; LÓPEZ REY, José A.

Del 0,7\% a la desobediencia civil: política e información del movimiento y la ONG de desarrollo (1994-2000). Madrid: Centro de Investigaciones Sociológicas. 2008.

JEREZ, Ariel; RAMOS, Alfredo; ALLEGRETTI, Giovanni.

Innovaciones participativas y deliberativas para la construcción de esferas públicas europeas. Encrucijadas, n.3, p.50-64. Disponible en: http://dialnet.unirioja.es/servlet/ articulo?codigo=3978097. Acceso en: 9 sep. 2014. 2012.
JEREZ, Ariel; RAMOS, Alfredo; ALLEGRETTI, Giovanni.

¿Con voz pero sin voto? Movimientos sociales y lobbies en los desarrollos recientes de la gobernanza europea. In: Díaz-Berrio, José Luis Escario (Coord.). Informe sobre el estado de la Unión Europea 2011: el año de la gran prueba. Madrid: Fundación Alternativas. p.35-48. Disponible en: http://dialnet.unirioja.es/servlet/ articulo?codigo=4757895. Acceso en: 9 set. 2014 . 2011.

KLUGE, Alexander; NEGT, Oskar. Esfera pública y experiencia: hacia un análisis de las esferas públicas burguesa y proletaria. In: Blanco, Paloma et al. (Ed.). Modos de hacer: arte crítico, esfera pública y acción directa. Salamanca: Ediciones Universidad de Salamanca. p.227-272. Disponible en: <http://dialnet. unirioja.es/servlet/articulo?codigo $=575093>$. Acceso en: 9 set. 2014. 2001.

LANDI, Sandro.

Opiniones y vínculo social: para una historia de la dimensión no discursiva de la esfera pública. Ariadna histórica: Lenguajes, conceptos, metáforas, v.2, p.51-80. Disponible en: http://www.ehu.es/ ojs/index.php/Ariadna/article/view/8737. Acceso en: 9 sep. 2014 . oct. 2013.

LOS PARTIDOS...

Los partidos políticos se desmoronan (Cuadernos n.3). Eldiario.es. 29 oct. 2013.

MANCINI, Paolo.

Hackear el periodismo: manual de laboratorio. Buenos Aires: La Crujia. 2011.

MARCO, Stefano De; ROBLES, José Manuel. Acción colectiva en internet: el surgimiento del movimiento social republicano de Beppe Grillo. Política y sociedad, v.48, n.1, p.75-93. Disponible en: http://dialnet.unirioja.es/servlet/ articulo?codigo=3643936. Acceso en: 9 set. 2014 . 2011.

MATTELART, Armand.

Historia de la sociedad de la información.

Barcelona: Paidós. 2002.

MONEDERO, Juan Carlos.

Dormíamos y despertamos: el 15M y la reinvencion de la democracia. Madrid: Nueva Utopia. 2012.

MONEDERO, Juan Carlos.

La transición contada a nuestros padres: nocturno de la democracia española. Madrid: Catarata. 2011.

NATANSON, Jose.

¿Por que los jóvenes están volviendo a la política?: de los indignados a La Cámpora. Buenos Aires: Debate. 2012. 
NAVARRO, Vicenç.

El subdesarrollo social de España: causas y consecuencias. Barcelona: Anagrama. 2006.

NAVARRO, Vicenç.

Bienestar insuficiente, democracia incompleta: de lo que no se habla en nuestro país. Barcelona: Anagrama. 2002.

ROMANOS, Eduardo.

Evictions, petitions and escraches: contentious housing in austerity Spain. Social Movement Studies, v.13, n.2, p.296-302. Disponible en: http://dx.doi.org/10.1080/14742837.2013.830567. Acceso en: 9 set. 2014. 12 sep. 2013.

ROMANOS, Eduardo.

El 15M y la democracia de los movimientos sociales: la vie des idées. Disponible en: http://www. booksandideas.net/El-15M-y-la-democracia-delos.html. Acceso en: 9 sep. 2014. 2011.

ROMANOS, Eduardo; SADABA, Igor.

La evolución de los marcos (tecno) discursivos del movimiento $15 \mathrm{M}$ y sus consecuencias. Empiria: Revista de Metodología de Ciencias Sociales, n.32, p.15-36. 2015.

SADABA, Igor.

Acción colectiva y movimientos sociales en las redes digitales: aspectos históricos y metodológicos. Arbor: Ciencia, Pensamiento y Cultura, v.188, n.756, p.781-794. 2012.

SAMPEDRO BLANCO, Víctor.

Podemos a la Parrilla (I). Disponible en: http://blogs.publico.es/el-cuarto-poder-en- red/2015/03/25/podemos-a-la-parrilla-i/. Acceso en: 9 oct. 2015. 25 mar. 2015.

SAMPEDRO BLANCO, Víctor.

Públicos y recursos tecnopolíticos: minorías insatisfechas y diques a la participación, In: Sampedro Blanco, Victor (Coord.). Cibercampaña: cauces y diques para la participación: las elecciones generales de 2008 y su proyección tecnopolítica. Madrid: Complutense. p.11-39. Disponible en: http://dialnet.unirioja.es/servlet/ articulo?codigo=4213853. Acceso en: 9 set. 2014 . 2011.

SAMPEDRO BLANCO, Víctor.

Opinión pública y democracia deliberativa: medios, sondeos y urnas. Madrid: Istmo. 2000.

SUBIRATS, Joan.

Otra sociedad, otra política?: de "no nos representan" a la democracia de lo común. Barcelona: Icaria. 2011.

TORET, Javier.

Una mirada tecnopolítica al primer año de Podemos: seis hipotesis. Teknokultura, v.12, n.1, p.121-135. 2015.

TORET, Javier et al.

Tecnopolítica y 15M: la potencia de las multitudes conectadas. Barcelona: UOC. 2015.

VVAA.

CT, o la cultura de la transición: crítica a 35 años de cultura española. Barcelona: Debolsillo. 2012.

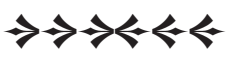

